\title{
Acute Cholecystitis After a Colonoscopy
}

\author{
Tae Ik Park, Sang Yong Lee, Jun Hee Lee, Min Cheol Kim, Bong Gap Kim, Dong Hyuk Cha ${ }^{1}$ \\ Department of Internal Medicine, Ilsin Christian Hospital, Busan; ${ }^{1}$ Department of Internal Medicine, Busan St. Mary’s Hospital, Busan, Korea
}

Acute cholecystitis after a colonoscopy is a rare event, and only eight documented cases are reported in the literature. A 35 -year-old male underwent a screening colonoscopy. There was a 5-mm sessile polyp in the sigmoid colon, which was removed by using a hot snare polypectomy. Forty-eight hours after the colonoscopy, the patient visited our emergency department with epigastric pain and fever. Based on the clinical findings, laboratory data and radiologic imaging, our diagnosis was acute cholecystitis. Because no previous cases of this type have been reported to date in Korea, we publish the details of our patients who presented with a postcolonoscopy complication diagnosed as acute cholecystitis.

\section{Keywords: Colonoscopy; Acute cholecystitis; Complications}

\section{INTRODUCTION}

Colonoscopy is a commonly performed procedure for the diagnosis and treatment of a gastrointestinal disease. Complications after a colonoscopy are rare, with perforation and hemorrhage being the most frequent $[1,2]$. Acute cholecystitis after a colonoscopy is a rare event, and no case has been reported to date in Korea. We report a case of acute cholecystitis after a colonoscopy.

\section{CASE REPORT}

A 35-year-old male underwent a screening colonoscopy. A 5-mmsized sessile polyp was noted in the sigmoid colon. After informed consent had been obtained, an uneventful hot snare polypectomy was performed. About 48 hours after the procedure, the patient visited the emergency room with epigastric pain. Physical examination revealed right upper quadrant and epigastric tenderness. The patient had a blood pressure of $150 / 90 \mathrm{mmHg}$, a heart rate of 105 beats/min, a respiratory rate of 22 times/min, and a body tem-

Received: January 29, 2013 - Accepted: April 10, 2013

Correspondence to: Sang Yong Lee, M.D.

Department of Internal Medicine, Ilsin Christian Hospital,

27 Jeonggongdan-ro, Dong-gu, Busan 601-724, Korea

Tel: +82-51-630-0498, Fax: +82-51-630-0682

E-mail: evergzone@nate.com

(C) 2013 The Korean Society of Coloproctology

This is an open-access article distributed under the terms of the Creative Commons Attribution NonCommercial License (http://creativecommons.org/licenses/by-nc/3.0) which permits unrestricted noncommercial use, distribution, and reproduction in any medium, provided the original work is properly cited. perature of $38.5^{\circ} \mathrm{C}$. Peripheral blood tests showed white blood cell, $13,300 \mathrm{~mm}^{2}$; neutrophils, $75.0 \%$; hemoglobin, $17.0 \mathrm{~g} / \mathrm{dL}$; and platelets, 309,000 $\mathrm{mm}^{2}$. Blood biochemistry showed total bilirubin $1.7 \mathrm{mg} / \mathrm{dL}$; serum glutamic oxalacetic transaminase, $42 \mathrm{IU} / \mathrm{L}$; serum glutamic pyruvic transaminase, $115 \mathrm{IU} / \mathrm{L}$; alkaline phosphatase, $263 \mathrm{IU} / \mathrm{L}$; blood urea nitrogen, $5.9 \mathrm{mg} / \mathrm{dL}$; creatinine, $1.1 \mathrm{mg} /$ $\mathrm{dL}$; and C-reactive peptide, $29.3 \mathrm{mg} / \mathrm{dL}$.

On a plain radiograph, no intraperitoneal air was seen. Abdominal computed tomography showed a $1-\mathrm{cm}$-sized gallstone in the gallbladder neck, which had a thickened wall and pericholecystic inflammation (Fig. 1). The patient was treated with intravenous antibiotics, and his symptoms and lab findings were improved within 3 days. He was discharged 7 days after admission and was given oral antibiotics; he planned to undergo a cholecystectomy.

\section{DISCUSSION}

Complications after a colonoscopy are rare, and perforation is the most common complication of this procedure. The rate of perforation reported in large studies is $0.3 \%$ or less and is generally less than $0.1 \%$ [3]. The second most common complication is hemorrhage, and other miscellaneous complications of a colonoscopy include splenic rupture, acute appendicitis, diverticulitis, subcutaneous emphysema, and tearing of mesenteric vessels with intraabdominal hemorrhage. Acute cholecystitis after a colonoscopy was first reported by Milman and Goldenberg [4]. All patients of the 8 cases reported in the literature had uneventful routine colonoscopies and developed cholecystitis within 72 hours after the procedures. Seven of them had concurrent cholelithiasis, and all pa- 

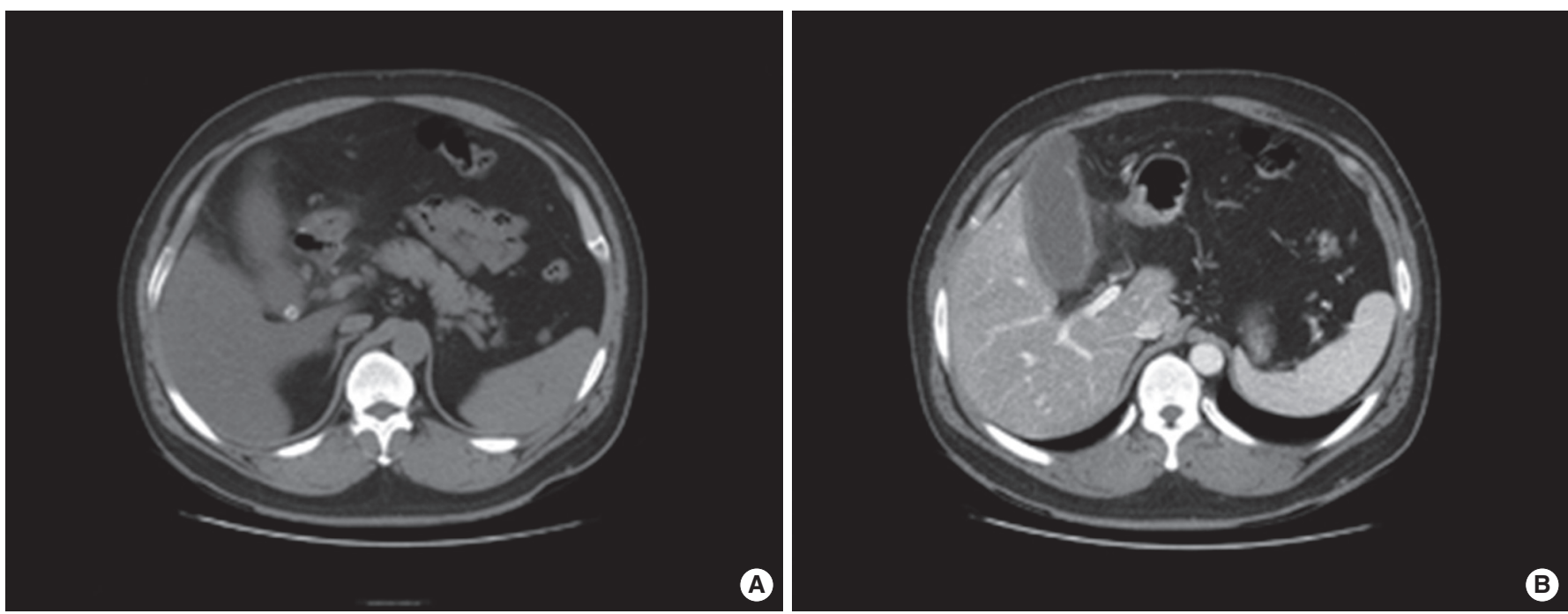

Fig. 1. Computed tomographic (CT) imaging findings. (A) Precontrast CT scan shows a gallstone in the gallbladder neck. (B) Contrast enhanced CT scan shows gallbladder wall thickening and pericholecystic inflammation.

Table 1. Summary of the cases

\begin{tabular}{lcllc}
\hline Author & Age (yr) & Gender & \multicolumn{1}{c}{ Colonoscopic procedure } & Colonoscopy to symptoms (hr) \\
\hline Milman and Goldenberg [4] & 58 & Female & Polypectomy (cold biopsy) & NR (<24) \\
Milman and Goldenberg [4] & 49 & Female & Random biopsy & 8 \\
Aziz et al. [5] & 63 & Female & Polypectomy & 74 \\
Aziz et al. [5] & 60 & Male & Polypectomy & 72 \\
Fernandez-Martinez et al. [6] & 76 & Male & Polypectomy (cold biopsy) & 48 \\
Maddur et al. [7] & 70 & Male & Polypectomy (cold snare and forceps) & 48 \\
Maddur et al. [7] & 70 & Male & Polypectomy (cold snare and snare electrocautery) & 72 \\
Maddur et al. [7] & 57 & Female & Polypectomy (snare electrocautery) & 48 \\
Present study & 35 & Male & Polypectomy (snare electrocautery) & 48 \\
\hline
\end{tabular}

NR, not reported.

tients recovered uneventfully after a cholecystectomy. All cases reported in literature are summarized in Table 1.

Some hypotheses have been suggested in the previous literature about the cause of acute cholecystitis after a colonoscopy. The relative dehydration caused by bowel preparation may make the patients more susceptible to developing acute cholecystitis. Dehydration caused by bowel preparation may lead to bile stasis, increased bile lithogenicity, and gallbladder distention, which increase the risk of a local inflammatory reaction [4]. In this setting, a preexisting gallstone can become impacted in the gallbladder neck or in the cystic duct [5], contributing to cholecystitis. Other proposed mechanisms are mechanical manipulation associated with bacterial translocation of the colon, and trauma or an adjacent inflammatory response from a polypectomy $[4,6,7]$.

Our patient had an uncomplicated, uneventful colonoscopy and developed cholecystitis 48 hours after the procedure. The patient likely had a longstanding asymptomatic gallstone that became symptomatic after the colonoscopy. Transient relative dehydration caused by bowel preparation may have made the bile more concentrated so that the preexisting stone became impacted in the gallbladder neck, leading to acute cholecystitis.

Although the reason our patient developed cholecystitis is not clear, the clinical characteristics and course of our case are correlated with those in the previous literature. While acute cholecystitis after a colonoscopy is a rare complication, we should consider cholecystitis in the differential diagnosis of postcolonoscopy abdominal pain and fever once common complications have been excluded.

\section{CONFLICT OF INTREST}

No potential conflict of interest relevant to this article was reported. 


\section{REFERENCES}

1. Lohsiriwat V. Colonoscopic perforation: incidence, risk factors, management and outcome. World J Gastroenterol 2010;16:425-30.

2. Rabeneck L, Paszat LF, Hilsden RJ, Saskin R, Leddin D, Grunfeld E, et al. Bleeding and perforation after outpatient colonoscopy and their risk factors in usual clinical practice. Gastroenterology 2008; 135:1899-1906.

3. Ko CW, Dominitz JA. Complications of colonoscopy: magnitude and management. Gastrointest Endosc Clin N Am 2010;20:659-71.
4. Milman PJ, Goldenberg SP. Colonoscopy cholecystitis. Am J Gastroenterol 2001;96:1666.

5. Aziz F, Milman P, McNelis J. Abdominal pain after colonoscopy: can it be acute cholecystitis? Dig Dis Sci 2007;52:2660-1.

6. Fernandez-Martinez C, Pla-Marti V, Flors-Alandi C, Roig-Vila JV. Gangrenous cholecystitis after colonoscopy. Am J Gastroenterol 2002;97:1572.

7. Maddur H, Agrawal S, Fayad N, Chalasani N, Kahi C. Acute cholecystitis after colonoscopy: a case series. Gastrointest Endosc 2011; 74:211-3. 